\title{
METAPSICOLOGIA SOBRE A FORÇA INCONSCIENTE DO PASSADO
}

\author{
Augusto B. De Carvalho Dias Leite \\ Universidade Federal do Espírito Santo \\ Vitória | Espírito Santo | Brasil \\ augustobrunoc@yahoo.com.br \\ orcid.org/0000-0001-6821-9074
}

Neste artigo, apresento os principais argumentos de Walter Benjamin acerca da centralidade do tempo passado para a constituição do fenômeno histórico através do reconhecimento de sua natureza inconsciente. Para tanto, evidencio particularmente as interpretações que Benjamin realiza da obra psicanalítica de Sigmund Freud, bem como da literatura de Marcel Proust. Defendo que Benjamin, retirando lições metapsicológicas da obra de Freud, as quais definem sua leitura filosófica de Proust, apresenta uma metapsicologia própria, que traduz conceitos da esfera individual para o âmbito coletivo da experiência. Assim, reitero a utilidade da tese benjaminiana que afirma a relevância do caráter inconsciente da consciência histórica através das ferramentas da metapsicologia.

metapsicologia - passado - inconsciente

Agradeço à Lorena Lopes, pela leitura do manuscrito deste artigo, pelas sugestões e correções; agradeço ao W alderez. Ramalho e ao Breno Mendes, pelo diálogo ininterrupto; agradeço ao Hugo Merlo e ao professor Julio Bentivoglio, pelo apoio e recepção de meu trabalho na UFES; agradeço à CAPES e à FAPES, pelo financiamento desta pesquisa. 


\title{
METAPSYCHOLOGY ON THE UNCONSCIOUS POWER OF THE PAST
}

\author{
Augusto B. De Carvalho Dias Leite \\ Universidade Federal do Espírito Santo \\ Vitória | Espírito Santo | Brazil \\ augustobrunoc@yahoo.com.br \\ orcid.org/0000-0001-6821-9074
}

In this essay I aim to show Walter Benjamin's main arguments about the centrality of the past for the constitution of the historical phenomenon through the recognition of its unconscious nature. I particularly highlight the interpretations that Benjamin makes of Sigmund Freud's psychoanalytic work, as well as of Marcel Proust's literature. I argue that Benjamin draws metapsychological lessons from Freud's oeuvre, which define his philosophical reading of Proust, and presents his own metapsychology, translating concepts from the individual sphere to the collective scope of the experience. Finally, I demonstrate the usefulness of the Benjaminian thesis that assert the relevance of the unconscious character of historical consciousness by means of metapsychology.

metapsychology - past - unconsciousness 


\section{O ReConhecimento do Passado COMO FORÇA EXISTENCIAL INCONSCIENTE FUNDAMENTAL}

O caráter inconsciente do tempo é uma antiga questão teórica do pensamento histórico moderno. Leopold von Ranke já afirmava que "o decisivo [para o pensamento histórico] é a origem. O primeiro passo é trabalhar continuamente em todo processo de desenvolvimento, seja consciente ou inconsciente" $(1867,345)$. Contudo, para "a teoria da história, essas camadas inconscientes da constituição histórica de sentido continuam a ser um campo ignoto, embora não se duvide do poder dos impulsos inconscientes do comportamento humano" (Rüsen 2015, 224); afinal, há "uma influência nada negligenciável de movimentos mentais inconscientes nos processos da constituição histórica de sentido" (2015, 93). Com efeito, existe uma demanda por teorizações que expliquem as características não-conscientes do fenômeno histórico, às quais Walter Benjamin se dedicou de maneira exaustiva, ressaltando, em suma, o papel essencial do passado na estrutura histórica de sentidos inconscientes.

Para o esclarecimento do estatuto inconsciente do passado como uma força existencial fundamental, Walter Benjamin dialoga com a teoria psicanalítica de Sigmund Freud, com Marcel Proust e, em um menor grau, com Henri Bergson. Da obra de Freud, Benjamin se interessa pela metapsicologia ${ }^{1}$, quer dizer, pelos pressupostos filosóficos gerais da psicanálise. Grosso modo, segundo a metapsicologia freudiana, as "influências do passado [...] recebidas dos outros" (GW XVII, 69) ${ }^{2}$ representam a principal fonte da matéria da existência; trata-se tanto de fatores hereditários - de um ponto de vista biológico - quanto de aspectos culturais (GW XIV, 504) - de um ponto de vista antropológico -, ou melhor, do seu "passado cultural" (GW XVII, 138), que se pode chamar igualmente de tradição - o que é transmitido. ${ }^{3}$ De acordo com a metapsicologia freudiana, portanto, apesar da vida se sujeitar invariavelmente ao poder do presente, do acidental e atual, à opressão do sucessivo, não há como negligenciar "as tendências herdadas, o passado orgânico", bem como o "passado cultural"; pois a "humanidade não vive inteiramente no presente. Nas ideologias do Super-Eu vive o passado, a tradição

${ }^{1}$ O neologismo freudiano metapsicologia [Metapsychologie] é o nome dado por Freud ao complexo de escritos técnicos e descritivos que apresentam de maneira objetiva não apenas análises, mas também as estruturas que fundamentam essas análises que a psicanálise produz enquanto método e ciência. O sentido geral da palavra diz respeito ao que está além ou antes da psicanálise como método aplicado de sua psicologia. Meta-psicologia, nesse sentido, não apenas nomeia um determinado tipo de forma temática dentro da ciência psicanalítica, mas, sobretudo, reúne os fundamentos gerais das estruturas psíquicas pressupostas pela análise. "Na medida em que Freud trabalhou com seu neologismo 'metapsicologia', que havia usado pela primeira vez numa carta a Fließ em 13 de fevereiro de 1896 [Freud-Fließ, p.181 (172)], ele passou a defini-lo de modo cada vez mais estrito, como uma psicologia que analisa as operações da mente a partir de três perspectivas: a dinâmica, a econômica e a topográfica. A primeira dessas perspectivas acarreta a sondagem dos fenômenos mentais, até as suas raízes nas forças inconscientes dominadas por conflitos, originadas principalmente das pulsões, mas não restritas a elas; a segunda tenta especificar as quantidades e as modificações das energias mentais; a terceira se encarrega de diferenciar os diversos domínios da mente. Juntas, essas perspectivas delimitadoras distinguiam claramente a psicanálise das outras psicologias" (Gay 1988, 334).

2 Os trabalhos completos de Freud, Gesammelte Werke (1949) e Studienausgabe (1975), serão referenciados como GW e SA, respectivamente, seguidos de tomo e paginação.

${ }^{3}$ Em "O papel da tradição na construção do mundo histórico" (2019a), explorei de forma mais detalhada o problema destacado por Freud, em diálogo com Walter Benjamin e Martin Heidegger. 
da raça e da nação, que dão lugar às influências do presente, muito lentamente" (GW VX, 73). Não obstante, há uma qualidade particular do passado que Freud sublinha: sua natureza escondida, esquecida, recalcada, reprimida, inconsciente; porque o passado somente existe de modo sempre contraditório, como presença ausente; o que torna o seu reconhecimento uma tarefa errante peculiar, um desafio para o pensamento. Em seu derradeiro texto, Freud afirma que todo o psíquico seria em si inconsciente (GW XVII, 147), composto assim por passados escondidos, esquecidos, mas ainda poderosos o suficiente para exercer sua força sobre nossa existência, escravizando nossa existência, nas palavras de Beatriz Sarlo $(2007,12)$. A característica recalcada, velada, aliás, seria uma das principais origens da força do passado. Jacques Lacan reitera os princípios dessa compreensão freudiana sobre o passado e o inconsciente, que significaria "alguma coisa da ordem do não-realizado" (1973, 31), espécie de experiência acumulada, consumada, mas a espera de significado retrospectivo - estrutura temporal implicada em toda obra freudiana (Derrida $1967,71)^{4}$

Benjamin, ressaltando a proeminência das conclusões metapsicológicas de Freud, resume a premissa em questão no texto sobre o conceito de história, em 1940, ao "reconhecer que a imagem da felicidade [desejos, futuros] que cultivamos está inteiramente tingida pelo tempo a que, uma vez por todas, nos remeteu o decurso de nossa existência" (GS I.2, 693). ${ }^{5}$ Para Benjamin, "com a representação do passado, que a História toma por sua causa, passa-se o mesmo" (GS I.2, 693). Entretanto, mais do que o passado que se transmite na superfície da consciência, há de se fazer justiça aos passados que se escondem inconscientemente, identificados como o "passado oprimido" (GS I.2, 703) pela transmissão cultural, que somente se torna acessível por meio do confronto com a tradição dos vencedores em favor do encontro do tempo passado perdido e esquecido. Segundo Benjamin, tal reconhecimento objetiva dar nome aos "sem nome" (GS 1.3, 1241), realizando, assim, uma outra historiografia que descubra, enfim, a natureza inconsciente da história ao resgatar do esquecimento os passados recalcados. Nesse sentido, a reflexão de Benjamin sobre a força inconsciente do passado se apresenta como um dos primeiros esforços para se compreender de forma adequada em que medida o material passado recalcado ou inconsciente mantém seu poder sobre a existência em geral, sobretudo sobre a chamada consciência histórica: a consciência da "historicidade do ser" própria ao pensamento histórico moderno (Cf. Gadamer 1963).

\footnotetext{
${ }^{4}$ Um tema fundamental da literatura metapsicológica é precisamente a natureza retrospectiva [nachträglich] de todo significado dado pela consciência a si mesma. "Não é o vivido em geral que é reinterpretado a posteriori, mas intencionalmente aquilo que no momento em que foi vivido não pode ser plenamente significativo" (Féve 2006, 764).

5 As referências aos trabalhos de Benjamin, Gesammelte Schriften (1991), e as suas cartas, Gesammelte Briefe (2000), serão feitas pelo uso de GS e GB, respectivamente, seguido do número do tomo e paginação. As traduções das teses "Sobre o conceito de história" são de JeanneMarie Gagnebin e Marcos Lutz Müller (Cf. Löwy 2005), com ligeiras modificações. A respeito da centralidade do tempo passado na obra de Walter Benjamin, tomo a liberdade de recomendar meu texto "Sobre o conceito de passado em Walter Benjamin" (2019b).
} 


\title{
Metapsicologia Coletiva Benjaminiana
}

\begin{abstract}
Existem, por exemplo, indicações de sua leitura de Freud no contexto dos estudos universitários (em 1918 ele frequentou o seminário de Paul Häberlein sobre Freud, em Berna), além de referências à 'doutrina do inconsciente' (Lehre von Unbewnßten) de Freud em sua discussão sobre o primário infantil na Frankfurter Zeitung de 13 de dezembro de $1930 \mathrm{sob}$ o título 'Chichleuchlauchra' (GS III, 271), e o 'estudo de Freud sobre o narcisismo' no mesmo jornal, na semana seguinte (GS III, 273). Fora isso, ele mesmo informa sobre sua leitura do ensaio de Freud sobre 'Psicanálise e Telepatia' (1934) em uma carta de 1935 para Gretel Adorno, bem como fala da 'Escola Freudiana' em seu ensaio sobre Bachofen do mesmo ano (GS II, 3, 935). Também, em 1935, ele escreve para Adorno dizendo que desejava 'comprometer-se' a ler Freud em um futuro próximo (GS, V, 2, 1121), como se ele não estivesse 'consciente' da intensidade de afinidades que há algum tempo ele tinha com a teoria freudiana. (Weigel 1996, 116-117).
\end{abstract}

Toda relação de Walter Benjamin com a obra de Sigmund Freud ou com a psicanálise se constrói mais indireta do que diretamente. De forma direta, a psicanálise - como método de análise - aparece em alguns trabalhos dos anos 1930. De modo indireto, temos a mémoire involontaire proustiana como um instrumento indispensável para Benjamin pensar a pesquisa e a escrita da história. Do uso da memória involuntária como agente realizador ou atualizador da existência histórica, pode-se inferir uma estrutura psíquica propriamente benjaminiana que, a rigor, não se iguala ao aparelho psíquico freudiano, mas corresponde a ele (através da obra de Proust).

$\mathrm{Na}$ estrutura psíquica assumida por Benjamin, a mémoire involontaire possui o mesmo papel que a memória inconsciente do aparelho psíquico da metapsicologia freudiana (ou são pelo menos similares) - os traços mnêmicos ${ }^{8} \mathrm{de}$ Freud praticamente nunca são conscientes (SA II, 516), situam-se no âmbito da não-intencionalidade do involuntário, tal como em Benjamin. Um exercício comparativo permitirá extrair tanto de Freud e da tradição psicanalítica quanto de Benjamin e da sua incursão na obra de Proust considerações que contribuam para a compreensão dos fenômenos não-conscientes ou nãointencionais, os quais, como se poderá averiguar, derivam particularmente da natureza do tempo passado. Martin Klüners, em Geschichtsphilosophie und Psychoanalyse (2013), ao analisar as relações entre psicanálise e a filosofia da história de Walter Benjamin, evoca o trabalho pioneiro de Jutta Wiegmann, Psychoanalytische Geschichtstheorie: eine Studie zur Freud-Rezeption Walter Benjamins (1989), o qual sublinha a transferência dos insights freudianos da esfera individual para o âmbito da história coletiva na obra de Benjamin. Wiegmann propõe que Benjamin realiza com a obra freudiana o que Stéphane Mosès

\footnotetext{
${ }^{6}$ Em uma lista bibliográfica de leitura Benjamin, além dos textos citados figuram: Der Witz und seine Beziehung zum Unbewußten; Psychoanalytische Bemerkungen über (einen autobiographisch beschriebenen Fall von Paranoia) (Fall Schreber) mit Nachtrag (in: "Sammlung kleiner Schriften zur Neurosenlehre«, 3. Folge, Leipzig, Wien 1913), Zur Einführung des Narzißmus (wahrscheinlich aus »Sammlung kleiner Schriften zur Neurosenlehre«, 4. Folge, Leipzig, Wien 1918); Über Psychoanalyse. Fünf Vorlesungen geh(alten) vor der Clark-University; todos textos de Freud (Cf. GS VII.1, 440-441; 443).

7 Vale ressaltar que atualizar, em Benjamin, não significa meramente presentificar ou encontrar sua forma no tempo presente, mas sim tornar ato um desejo latente ou uma intenção suspensa.

8 “'D]as percepções que chegam até nós, permanecem em nosso aparato psíquico um vestígio ou rastros que nós podemos chamar de 'traços mnêmicos' (...). A função a que se refere esse traço mnêmico chamamos de 'memória"' (SA II, 514).
} 
(2006, 208) afirma ser o procedimento geral de Benjamin, a saber, a articulação coletiva da individualidade. "De acordo com Jutta Wiegmann, Benjamin traduz ideias freudianas, sobretudo as teorias sobre o trauma e o recalque, "para a história coletiva"' (Klüners 2013, 124). Ou seja, aquilo que Freud e a literatura sobre a não-intencionalidade tratam como fato individual, Benjamin desenvolve em forma de fato coletivo ou próprio à história. Se para Freud e os estudos sobre a não-intencionalidade, o corpo é o centro gravitacional de toda articulação teórica sobre a experiência, não haverá diferenciação entre corpo individual e coletivo em Benjamin; pois "o coletivo é corporal” (GS II.1, 310). O coletivo (o social, a sociedade, a história) é um corpo, precisamente, porque ele apenas se materializa ou se objetiva por um meio material especifico, um corpo, através da memória (voluntária e involuntária) e a sua capacidade conjuntiva - algo que a nomenclatura conceitual benjaminiana traduz de maneira a fundamentar sua arquitetura teórica onto-epistemológica, pois "[s]e há experiência no sentido estrito do termo, conteúdos do passado individual e coletivo entram em conjunção na memória" (GS I.2, 611). Da perspectiva filosófica, trata-se de uma afirmação fundamentalmente fenomenológica, pois "de acordo com a fenomenologia, o $E$, o mundo, e os outros, devem estar juntos, eles reciprocamente iluminam um ao outro, e apenas podem ser entendidos em interconexão" (Zahavi 2009, 185). Com efeito, apesar da divisão entre metapsicologia e psicologia ser apenas formal, do ponto de vista da psicanálise, Benjamin, então, aborda a metapsicologia freudiana filosoficamente e de maneira isolada, não interessado na psicanálise enquanto prática curativa.

\section{Metapsicologia Benjaminiana Aplicada À Crítíca Cultural E dA IdeIA dE TEMPO}

Freud é citado diretamente por Benjamin em Über einige Motive bei Baudelaire (GS I.2, 605-653), a segunda versão do trabalho sobre Baudelaire encomendado pelo Institut für Sozialforschung - quando ele já está exilado em Nova Iorque. O texto é fruto de um esforço intenso de Benjamin para elaboração de uma teoria do conhecimento, trabalho epistemológico exposto em uma troca de cartas com Adorno (Cf. Otte 2007). Esse segundo ensaio sobre Baudelaire é o texto de Benjamin que melhor analisa, através da estrutura de interpretação psicanalítica, o século XIX europeu sob a ótica baudelairiana. A ideia do choque [Chock], os traumas oriundos do choque, a perda de experiência [Erfahrung] em detrimento da efêmera vivência [Erlebnis] própria à modernidade capitalista europeia são elementos interpretativos que carregam significados deduzidos das investigações psicanalíticas. Enfim, trata-se de um texto diretamente determinado pela psicanálise freudiana. Por outro lado, há uma série de reflexões teóricas que Benjamin tece por meio da literatura freudiana, mas que, a rigor, não são interpretações da realidade oriundas do aparato psicanalítico; ao contrário, são casos em que a metapsicologia freudiana e seus conceitos são mobilizados por Benjamin como ferramentas para a posterior interpretação, não como elementos prontos que carregam em si algum significado pré-articulado. Como se lê em uma nota intempestiva: "a mémoire involontaire é associada à experiência, não à vivência. (Freud!) A experiência é fruto do trabalho, a vivência (choque) é fruto da ociosidade" (GS I.3, 1183). 
Tais investigações teóricas estão registradas na obra das Passagens convolutos $\mathrm{K}$ e $\mathrm{N}$, especialmente -, em fragmentos variados do espólio - em grande parte publicado no volume VI dos trabalhos reunidos - e ainda no texto sobre o conceito de história. Sérgio Paulo Rouanet, em Édipo e o Anjo: itinerários freudianos em Walter Benjamin (1981), analisa a incursão psicanalítica de Benjamin e descreve detalhadamente o desenvolvimento da "teoria freudiana sobre a correlação entre memória e consciência, na perspectiva de uma crítica da cultura" (Rouanet 1981, 44), em Über einige Motive bei Baudelaire. Benjamin explora a relação entre memória e consciência para, então, explicar o porquê da queda da experiência dentro da modernidade. A explicação benjaminiana reside nos constantes choques aos quais o indivíduo moderno está submetido, mantendo a sua atenção alerta e a sua memória vazia de conteúdo, precisamente pelo fato da consciência se comportar como escudo protetor [Reizschut:] (GS I.2, 613); quer dizer, a consciência agindo através do princípio de realidade freudiano. Esse esquema se explica segundo o jogo entre princípio do prazer e princípio de realidade (SA III, 375) tal como apresentado no primeiro capítulo de Jenseits des Lustprinzips (1920), obra largamente citada por Benjamin no ensaio em questão. "Essa leitura da teoria freudiana do choque constitui a chave da crítica cultural de Benjamin" (Rouanet 1981, 45).

Em relação à crítica a ideia de tempo metapsicológica de Benjamin, apesar do texto Berliner Kindheit um neunzehnhundert e as suas variantes operarem a partir do esquema freudiano sobre a memória, será na última versão do texto sobre Baudelaire, publicado finalmente na Zeitschrift für Sozialforschung em 1940, que se desenvolverá a conceitualização específica do passado em conexão com Freud - além de Bergson e principalmente Proust - de modo explícito. Freud é então citado à exaustão, juntamente com a obra de Theodor Reik, Der überraschte Psychologe. Über Erraten und Verstehen unbewußter Vorgänge (1935) (Schmider; Werner 2011, 574). Os conceitos de Erinnerung [lembrança] e Gedächtnis [memória] são deliberadamente mobilizados a partir da perspectiva freudiana, juntamente com a ideia de mémoire involontaire proustiana que, pelo emprego de Benjamin, compõe a leitura do que é propriamente involuntário ou não-intencional - objeto singular de Benjamin a partir dos anos 1930 e que, mais do que fundamentar, também estabelece a estrutura da sua arquitetura da temporalidade (Cf. Raulet 1996).

\section{Mémoire involontaire e Unbewußte}

A memória involuntária de Benjamin obedece à estrutura inconsciente de metapsicologia de Freud. É preciso delimitar, contudo, a diferença entre a incursão psicanalítica e as afinidades e diferenças metapsicológicas que a teorização de Benjamin possui em relação ao pensamento freudiano. Portanto,

9 Sobre esse texto específico, Nadine Werner realiza um estudo histórico-filológico profundo e traça as afinidades entre Benjamin e Freud em Archäologie des Erinnerns. Sigmund Freud in Walter Benjamins Berliner Kindheit (Cf. Werner, 2015). "O propósito do livro é claro: tratase de "uma pesquisa sistemática das posições teóricas sobre o lembrar em Benjamin que remetem a Freud" e isso em particular na Infância em Berlim. O leitor não encontrará, portanto, reflexões de Benjamin a partir da teoria do desejo, do sonho ou mesmo da infância em Freud, mas uma "comparação" cerrada entre as teorias da memória ("Gedächtnis") e da lembrança ou do lembrar ("Erinnerung") em ambos os autores. Nadine Werner nota que a pesquisa benjaminiana tratou muito mais dos paralelos entre Proust e Benjamin, no que diz respeito à memória, e negligenciou aqueles, segundo ela essenciais, entre Freud e Benjamin. Isso talvez explique uma certa má vontade sua em relação à importância de Proust para a leitura de Benjamin, em detrimento de Freud” (Gagnebin 2016, 405). 
as conexões teóricas emergem por meio da pergunta: "em que condições pode a mémoire involontaire evocar uma memória?" (Raulet 1996, 12). Em pelo menos duas ocasiões, no ensaio sobre Baudelaire, Benjamin responde a essa questão e demonstra os elos conceituais que animam o debate organizado nesse artigo, que desenha a condição das correspondances baudelairianas, particularmente a estrutura de temporalidade, sempre sob o prisma da não-intencionalidade (Schlossman 1992).

Caso se acredite em Bergson, é rememorando a durée que a alma humana se libera da obsessão do tempo. Proust compartilha dessa crença e tem nela os exercícios com os quais buscou durante toda a vida trazer à luz um passado saturado de todas as reminiscências que o impregnaram durante a sua permanência no inconsciente. (GS I.2, 637). ${ }^{10}$

E ainda:

Em busca de uma definição mais concreta do que a que aparece na mémoire de l'intelligence de Proust, como subproduto da teoria bergsoniana, é oportuno remontar a Freud. Em 1921 aparece o ensaio Além do Princípio do Praz̧er, que estabelece uma correlação entre a memória (no sentido de mémoire involontaire) e a consciência. Essa correlação é apresentada como uma hipótese. As reflexões seguintes, que a ela se referem, não pretendem demonstrá-la. Limitam-se a experimentar a fecundidade desta hipótese sobre nexos muito remotos em relação àqueles que Freud tinha presentes no momento de formulá-la.

(GS I.2, 612).

Reitero: em que medida pode-se falar em memória ao se falar em mémoire involontaire? Para responder a essa interrogação, Benjamin articula Bergson e Freud em torno de Proust, o seu principal teórico do tempo, pois $\grave{A}$ la Recherche du Temps Perdu (1913-1927) é a obra que funda a compreensão da temporalidade no seu aspecto não-intencional para Benjamin - Zum Bilde Prousts (1929) demonstra o impacto que a leitura e o estudo da Recherche causa na conceptualização benjaminiana sobre a memória e o tempo. Em Proust, o tempo perdido é sempre tempo passado, assim como para Benjamin o tempo misterioso da experiência esquecida é igualmente o tempo passado, razão primeira da possibilidade de experimentar o tempo involuntário, nãointencional, inconsciente. Como se pode ler no primeiro volume da série, $D u$ Côté de chez Swann (1913): "é um esforço perdido procurar evocá-lo [o passado inconsciente], todos os esforços de nossa inteligência são inúteis. Ele está escondido fora de seu domínio e de seu alcance, em algum objeto material (na sensação que nos daria esse objeto material), que nós nem mesmo suspeitamos" (Proust 1988, 44). Eis o fundamento não-intencional da temporalidade proustiana, citado, inclusive, no ensaio de Benjamin sobre Baudelaire (GS I.2, 610): o tempo se esconde, aparece à consciência de forma velada porque seu fundamento, o passado, configura-se permanentemente de maneira não-intencional. Proust, em entrevista concedida ao periódico Le Temps, no ano de publicação do primeiro volume de Recherche, 1913, ao comentar os princípios filosóficos da sua obra, adiantando-se em relação ao que Benjamin fará em 1939 - ano de escrita do seu ensaio -, afirma que a sua obra, por meio do trabalho da não-intencionalidade própria à mémoire involontaire, deve ser lido como um "romance do inconsciente".

10 A tradução é retirada do volume III das Obras Escolbidas (Benjamin 2004), com algumas alterações. 
Desse ponto de vista, continua o Sr. Proust, meu livro será talvez como um ensaio de uma sequência de 'Romances do inconsciente'. Não teria nenhuma vergonha em dizer 'romance bergsoniano', se eu assim acreditasse, pois em toda época a literatura procurou se ligar - a posteriori, naturalmente - à filosofia reinante. Mas não será exato, porque minha obra é dominada pela distinção entre memória voluntária e memória involuntária, distinção que não somente não se encontra na filosofia do Sr. Bergson, mas até mesmo a contradiz.

- Como o senhor estabelece essa distinção?

- Para mim, a memória voluntária, que é sobretudo uma memória da inteligência e dos olhos, não nos apresenta senão a face inverídica do passado; um odor, um sabor encontrado em circunstâncias totalmente diferentes, ao despertar em nós, apesar de nós mesmos, o passado, sentimos o quanto o passado foi diferente daquilo que acreditamos lembrar e que nossa memória voluntária pinta, como os maus pintores, com cores sem verdade. Já no primeiro volume, o senhor verá o personagem que conta, que diz: 'Eu' (e que não sou eu), reencontra de uma vez só os anos, os jardins, os seres esquecidos, no gosto de um gole de chá onde ele molhou um pedaço de madeleine (...).

Veja o senhor, eu acredito que o artista deveria demandar a matéria prima da sua obra principalmente das memórias involuntárias. Primeiro, precisamente porque são involuntárias, formam-se delas mesmas, atraídas pela afinidade de um minuto idêntico e são por si sós uma marca de autenticidade. Em seguida, elas nos mostram as coisas em uma dosagem exata de memória e esquecimento. E, enfim, como elas nos fizeram provar a mesma sensação em uma circunstância diferente, elas são liberadas de toda contingência, elas nos dão a essência extratemporal, aquela que é justamente o conteúdo do bom estilo, a verdade geral e necessária que a beleza do estilo traduz.

(Proust 1988: 452-453). ${ }^{11}$

A obra de Proust é um romance sobre o inconsciente; mais afeita a essa estrutura, aliás, do que ao bergsonismo coevo - que igualmente determinada o tempo passado como fundamento da experiência do tempo (Cf. Vetö 2005) -, apesar de certas analogias que ele mesmo e Benjamin sugerem entre a sua obra e a filosofia de Bergson. "A estrutura das vivências genuínas por Freud e Proust" (GS VII.2, 743) é o objeto de estudo declarado de Benjamin. Quer dizer, Freud parece ter mais em comum com Proust do que com Bergson; a memória involuntária (de Proust) e o inconsciente (de Freud) são relacionados pelo próprio Proust, algo que Benjamin também enxerga ao mobilizar Proust junto a Freud, a fim de estruturar a arquitetura não-intencional do tempo. Proust fala em compreensão aprés coup, retrospectiva, outra nomenclatura freudiana que parece impregnar a explicação que Proust dá de si mesmo. De modo direto, todavia, em uma carta a Adorno, de 7 de maio de 1940, Benjamin afirma: "a experiência infantil do gosto da Madeleine, que Proust um dia involuntariamente de novo rememorou, foi na verdade inconsciente" (GB VI, 446).

Para Benjamin, a memória involuntária e o inconsciente situam-se no mesmo plano teórico, quer dizer, um mesmo plano filosófico fenomenológico; quando se fala em memória involuntária ou inconsciente, refere-se a um mesmo fenômeno que se origina de determinada experiência temporal encontrada sempre no tempo passado, a inconsciência. Dito isso, é preciso considerar também que, como já dito, Bergson - além de Proust e Freud - figura entre os principais mediadores da perscrutação benjaminiana sobre Baudelaire, conforme o próprio Benjamin indica em dois resumos (um em alemão e outro em francês) escritos para a revista do Instituto de Pesquisa Social (Cf. GS I.3, 1186-1188). Bergson funciona

${ }^{11}$ Entrevista concedida a Élie-Joseph Bois, do jornal Le temps, no dia 13/11/1913. 
como uma "autoridade de época" que lastreia o uso do Proust como epistemólogo, através de comparações da Recherche, de Proust, com Matière et Mémoire (1896), de Bergson. Para Benjamin, "a memória pura - a mémoire pure da teoria bergsoniana tornou-se mémoire involuntaire em Proust" (GS I.2, 609), ou seja, a memória involuntária de Proust, para Benjamin, possui lógica similar ao conceito de Bergson. Além disso, "ele [Benjamin] entende mémoire involontaire como a forma particular de memória que evoca não só o que foi inconscientemente esquecido, mas também as experiências inconscientemente experienciadas" (Raulet 1996, 12); memória involuntária significa a origem da experiência em geral, de acordo com Benjamin.

Jeanne-Marie Gagnebin resume bem a questão nos seguintes termos:

\begin{abstract}
Os dois autores [Freud e Proust] dedicam sua atenção justamente a essas imagens - inconscientes, diz Freud, involuntárias, diz Proust -; uma atenção paradoxal, certamente, leve e intensa, uma 'atenção flutuante'. Eles ouvem os zunidos que perturbam o discurso consciente e bem ordenado do sujeito, tentando perceber o que esses ruídos parasitários podem significar. Se a tradição se ocupou sobretudo do processo consciente da recordação, Freud e Proust empreenderão um deslocamento do olhar, atentando para as imagens da lembrança que o sujeito não escolhe e que podem até incomodar ou assustar, mas também provocar surpresas e reencontros felizes. Esse deslocamento traduz uma transformação da teoria da memória e, mais profundamente, uma transformação da própria concepção de sujeito. Esse não é mais definido antes de tudo por sua atividade consciente, voluntária, autônoma, mas também por um tipo de faculdade passiva, receptiva, de acolhimento, que a filosofia reservara antigamente à matéria - e às mulheres...! Tal receptividade passa então a ser interpretada não em termos de inércia, mas em termos positivos de disponibilidade atenta. $(2014,240)$.
\end{abstract}

\title{
Surrealismo e imagem dialética
}

Assim como demonstrado até aqui, Benjamin se corresponde com o trabalho metapsicológico de Freud de maneira significativa. Essa correspondência estabelece-se, notadamente, pela via indireta de Proust, mas também pelo contato com os surrealistas, que fundam o seu movimento estético por meio do reconhecimento da natureza inconsciente da consciência. Nesse sentido, a obra surrealista expressa o subterrâneo recém-descoberto do espírito ou da memória, através de procedimentos experimentais - a écriture automatique de Breton, por exemplo - que animam a não-intencionalidade e a sua potência reveladora do inconsciente. Não é sem motivos que Breton, em Manifeste du surréalisme (1924) rende graças a Freud (1985, 20), num elogio detalhadamente exposto em Der Sürrealismus. Die Letżte Momentaufnabme Der Europäischen Intelligen ₹ (1929), de Walter Benjamin.

Com efeito, averigua-se que a escrita e o pensamento de Benjamin estão impregnados pela metapsicologia freudiana de maneira dupla, assim como ele mesmo diz sobre a teologia, no conhecido fragmento do trabalho das Passagens (GS V.1, 588 [N7 a,7]), o que Gérard Raulet corrobora no seu estudo sobre o Historismus em Benjamin. Raulet, assim como Weigel, a partir do trabalho filológico detalhado de Josef Fürnkäs (1998), demonstra que toda a estrutura fundada por Benjamin para a sua crítica à ideia de história segue ou persegue o caminho pavimentado por Freud e os surrealistas. "Em Freud e nos surrealistas, Benjamin busca uma saída do âmbito do voluntário, o que produziu a sua crítica da razão histórica e da experiência histórica” $(1992,116)$. 
Raulet ainda destaca que o involuntário (ou não-intencional) em Benjamin emerge sempre sob a sombra do aparelho psíquico que a metapsicologia freudiana estabelece. É possível, portanto, determinando a correspondência entre aquilo que Benjamin circunscreve ao âmbito do involuntário e aquilo que Freud circunscreve ao âmbito do inconsciente, enriquecer a compreensão do que Benjamin propõe para a refundação da ideia de história moderna - crítica radicalmente enraizada na obra de Proust e determinada pelo conceito de mémoire involontaire. Assim, pode-se concluir junto a Raulet que

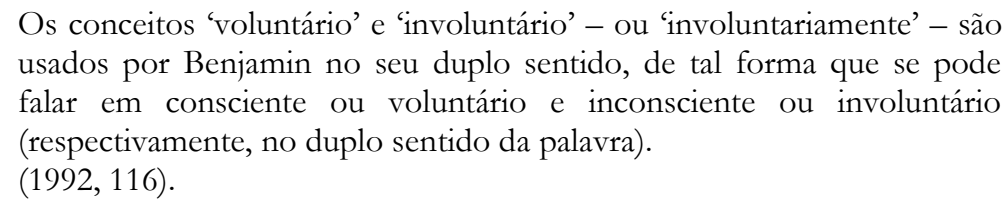

A chamada imagem dialética de Benjamin, coeficiente material da natureza histórica que resulta do movimento próprio aos variados índices históricos que cada passado carrega, é resultado involuntário ou inconsciente do caráter do tempo. "A 'memória involuntária' fora compreendida como uma memória não 'voluntária' (no 'mau' sentido) e assim entende Benjamin ser ela a 'imagem dialética" (Raulet 1992, 116), pois "a imagem dialética é assim definida como a memória involuntária da humanidade redimida" (GS I.3, 1233) e tal imagem obedece sempre às leis da descontinuidade (GS I.3, 1236) do tempo; isto é, são imagens ou interpretações sobre a histórica que somente aparecem em determinada época porque são legíveis em determinada época. Essa estrutura de atualização do tempo, ou seja, a forma de tornar ato aquilo que é transitivo, aquilo que é-no-tempo, a imagem dialética de Benjamin, tanto exprime o movimento próprio ao tempo enquanto fenômeno como expressa a sua interrupção, duas características originais da temporalidade que o conceito de passado freudiano anuncia. É próprio ao passado inconsciente freudiano o movimento e a interrupção; quer dizer, passado para Freud significa a experiência que ganha sentido apenas quando provocada por algum índice de sua atualidade retrospectivamente, o que interrompe a inércia inconsciente para fazer saltar à consciência determinado traço mnêmico - ou vestígio da memória - que antes adormecia escondido no inconsciente. A imagem dialética funciona precisamente a partir desse tipo de interrupção do tempo no agora da sua cognoscibilidade (GS V.1, 577-578 [N 3, 1]), quer dizer, no momento que ganha sentido.

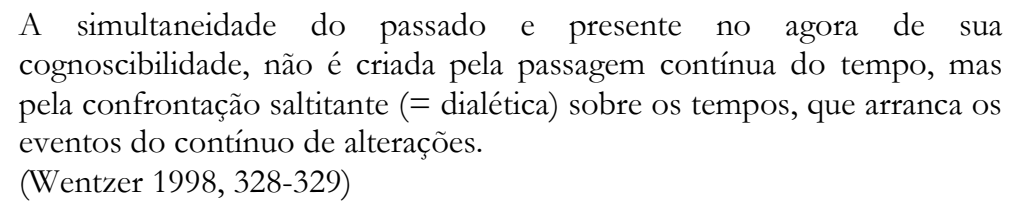
cognoscibilidade, não é criada pela passagem contínua do tempo, mas pela confrontação saltitante (= dialética) sobre os tempos, que arranca os eventos do contínuo de alterações.

(Wentzer 1998, 328-329)

Há, portanto, certa correspondência ou intimidade entre as formas conceituais que Freud e Benjamin, pela via proustiana, empregam para a compreensão da esfera não-intencional própria à experiência. A interminável plasticidade do passado, da qual falou Max Scheler (Raulet 1992, 116; Kittsteiner 1986, 191), encontra-se em Benjamin e se orienta pela nãointencionalidade, pelo caráter involuntário ou inconsciente que, por sua vez, orienta-se pelo material esquecido (Proust) ou recalcado (Freud) próprio ao que é passado. 


\section{Metapsicologia Benjaminiana do CORPo}

A não-intencionalidade (GS I.1, 216) - o aspecto inconsciente ou involuntário da experiência individual e coletiva - é, em Benjamin, indissociável daquilo que a literatura benjaminiana não cessa de alocar no centro da discussão sobre a constituição do conhecimento: o "minúsculo e frágil corpo humano" (GS II.2, 439). A coletividade é como um grande corpo constituído de pequenos corpos, pois para Benjamin "o coletivo é corporal" (GS II.1, 310). "Os traços nos escritos de Benjamin sobre o corpo - aparecem ambos especificamente como corpóreo (Leib) e sob o termo genérico para o corpo, ou massa (Körper)" (Weigel 1996, 23). Esse corpo (ou massa corporal) [Körper] é então compreendido por Benjamin como unidade corpo [Leib] e espirito [Geist], "eles são idênticos, diferenciando-se apenas pelo ponto de vista, não enquanto objetos" (GS VI, 79) ${ }^{12}$. Tal como salientado pela crítica cultural de Benjamin, o corpo é posto à prova, sempre, pelo contato cotidiano ou convívio com os objetos e o mundo circundante. Dessa relação, a idealização (construção de ideias) do mundo empírico e também histórico encontra a sua forma - o que aparecerá nas perscrutações epistêmicas do prefácio à obra sobre o drama trágico ou barroco alemão, em 1925, e também no aparato teórico crítico ao trabalho das Passagens, especialmente nos arquivos $\mathrm{K}$ e N. A ideia do corpo que na sua totalidade agremia a potencialidade criativa é, além disso, também fundamentada por Proust, pelos surrealistas e por Freud, de modo metapsicológico; fato que já pode ser notado em 1918, quando Benjamin elabora uma pequena nota sobre a relação entre a espontaneidade, $\mathrm{o}$ livre arbítrio e o corpo. No pequeno fragmento em questão, embora de forma bastante rudimentar, Benjamin deixa clara a sua preocupação com aquilo que foge ao alcance do controle da razão, o teor não-intencional das ações humanas, que emerge do substrato original constituinte do inconsciente, aquilo que Freud chamará de instintos ou pulsões [Triebe] (SA III, 82), trazendo a corporeidade e as suas potencialidades para o centro da discussão. Mesmo sendo difícil afirmar categoricamente que o vocabulário metapsicológico de Freud seja evocado por Benjamin neste fragmento, o fato do pronome pessoal "eu" [ich] ser empregado com a primeira letra maiúscula [Ich] é relevante. Da forma como se encontra no fragmento, como substantivo, o $E u$ [Ich], com a primeira letra maiúscula, pode remeter ao vocabulário técnico metapsicológico de Freud: o Eu ou o Ego. Esse argumento ganha força quando se lembra que, no mesmo ano de escrita do fragmento em questão, Benjamin frequentou o seminário do professor Paul Häberlein, em Bern, sobre a doutrina do inconsciente [Lehre von Unbewnßten] de Freud (Cf. GS VI, 674) ${ }^{13}$ (Weigel 1996, 116). Em outras palavras, Benjamin comentaria em 1918, no fragmento $<\mathrm{f}$

\footnotetext{
12 A cisão corpo e alma, tradicional esquema da metafísica e da ontologia, tendo no cogito cartesiano a sua expressão moderna, será radicalmente colocada em questão por Benjamin, assim como por outros pensadores da virada do séc. XIX para o XX, como Heidegger em Sein und Zeit. "Se a história consagrada da filosofia, tomando em particular Koyré, via na geometrização e matematização da physis - na mecanização da natureza - o advento do moderno; se a visão hegeliana apontava a grande revolução do séc. XVII na descoberta da consciência de si reflexiva, Benjamin surpreenderá: "o elemento barroco do racionalismo cartesiano" é a intransponível cisão corpo e alma, de tal forma que é apenas no instante da morte que "finalmente o corpo se liberta dessa alma", estando o orgânico mais próximo ao inorgânico e ao inumano" (Matos 1993, 21). Tal distinção entre Leib e Körper averigua-se já em Husserl como distinção fenomenológica (Zahavi 2009, 181).

13 Häberlein teve, naquele período, entre os seus temas centrais as relações entre corporeidade e alma, como bem indica o título da sua obra Leib und Seele, de 1920.
} 
36> (GS VI, 55), sobre o aparato psíquico freudiano - que a literatura psicanalítica trata de formalizar em 1915 -, sugerindo possuir certo conhecimento da metapsicologia.

A ESPONTANEIDADE do Eu é bastante distinta da liberdade do indivíduo. A questão do livre-arbítrio é sempre erradamente baseada na espontaneidade, assim é também com a questão sobre a liberdade do ato de pensamento ou da mera ação corpórea. Tal coisa não existe. $\mathrm{O}$ indivíduo pode ser livre apenas em relação aos atos que foram pensados. A pergunta sobre a espontaneidade do Eu [ou Ego] pertence a uma conexão completamente diferente (biológica??). (GS VI, 55).

A sombra que a metapsicologia freudiana produz sobre o trabalho de Benjamin, da qual fala o professor Gérard Raulet $(1992,116)$, verifica-se então a partir desse pequeno esforço filológico. $\mathrm{O} E u$ e a sua espontaneidade própria - destacados na sua breve reflexão - são colocados em relação possivelmente biológico-fisiológica com a liberdade, o que, em Freud, funciona como relação psíquica que se organiza tanto pela biologia (pulsões) quanto pela psicologia (desejos), confirmando em parte a suspeita de Benjamin. E é relevante a dúvida sublinhada por Benjamin ao final, em relação aos problemas próprios à metapsicologia, que diz respeito não só ao conhecimento flagrante de Benjamin sobre a literatura freudiana, mas do início da ocupação do pensamento benjaminiano com o cogito cartesiano, cujos princípios básicos - a saber, a separação do corpo e da alma ou da razão e do irracional - são artificiais, tal como o são para Freud.

O corpo e o Eu, mesmo que de maneira pouco detalhada, tornam-se objeto de Benjamin. Esse fragmento de 1918 reitera a tese de que a metapsicologia não lhe era estranha. A preocupação de Benjamin com o corpo e as implicações que a criatividade corporal tem para a constituição do conhecimento em geral não deixarão de persistir nos seus textos. Em uma variante da teoria mimética de 1933, Benjamin, em 1936, registra em outro breve fragmento que o corpo [Körper], como unidade entre corpo e espírito, é de fato o primeiro material no qual a faculdade mimética ou criativa é posta à prova (GS VI, 127).

Pois toda reatividade da vida é ligada a uma diferenciação, cujo mais nobre instrumento é o corpo. Esse seu propósito é compreendido como essencial. O corpo como um instrumento de diferenciação [Differenzierungsinstrument], a reação vital (...). (GS VI, 81).

O corpo é, pois, um instrumento de diferenciação, deformação ou refração. Benjamin segue, nestes termos, os passos do Proust epistemólogo, pois sabe que "o espírito não é um soberano absoluto (...) ele depende do corpo, dos sentidos e dos outros" (Gagnebin 2006, 558). Tal como Franz Rosenzweig anuncia em Der Stern der Erlösung (1921), o intelecto possui uma confiabilidade [Vertranenswürdigkeit] $(2002,431)$ nos sentidos, e seria essa confiabilidade ou potência para se confiar em si mesmo que faria a não-intencionalidade também emergir, sendo ela uma das origens do conhecimento e da verdade enquanto revelação da presença das coisas, pois "a verdade é um construto de ideias sem intenção" (GS I.1, 216), de acordo com Benjamin. A verdade ou como as coisas se revelam, como ele próprio afirma categoricamente, "é a morte da intenção" (GS I.1, 216) - intenção dos sentidos e intenção do corpo; isto é, a verdade se revela apenas pela via da não-intencionalidade. 
Expressados pelo corpo na sua totalidade, todos os sentidos - a partir do que Agostinho chamou de "concupiscência dos olhos", resumo da capacidade "canibalesca" dos sentidos humanos - têm em comum o objetivo ou a vontade de extinguir o tempo, aproximando os objetos e as coisas, destruindo o espaço entre ente e ser, fazendo as coisas retornarem ao interior que não é interior, mas constitui a espacialidade total que o corpo possui junto aos objetos, às coisas e ao mundo. A absorção do mundo empírico da qual fala Benjamin (GS I.1, 2012) objetivaria a destruição da materialidade do mundo a fim de recriá-lo, transubstanciando o mundo pré-concupiscência em um mundo pós-concupiscência; transformando o mundo material em um mundo ideal, através da potencialidade criativa e vital do corpo. Reside, portanto, no corpo - como instrumento de diferenciação do mundo - a capacidade de transformar o intemporal em temporal, de temporalizar a temporalidade ou de transformar o inconsciente em consciência, nas palavras de Freud, o que, em Benjamin, afirma-se naquilo que ele chamou de imagem dialética: imagens sobre a história que estariam escondidas, mas à espera de serem reveladas através de sua atualidade.

\section{METAPSICOLOGIA DA INCONSCIÊNCIA HISTÓRICA OU SOBRE O INCONSCIENTE DO ESQUECIMENTO}

Em um comentário ao artigo "Préface à l'éloge des préjugés populaires", do médico Pierre Mabille, amigo de André Breton e membro do círculo surrealista de Paris, publicado na revista Minotaure, "revue artistique et littéraire", Benjamin propõe o confronto entre as duas formas que o inconsciente possuiria, de acordo com Mabille, quais sejam, inconsciente "visceral" e inconsciente "do esquecimento".

Confronto entre o 'inconsciente visceral' e o 'inconsciente do esquecimento', sendo o primeiro predominantemente individual, e o segundo predominantemente coletivo. 'A outra parte do inconsciente é feita da massa de coisas aprendidas ao longo dos anos ou ao longo da vida, que foram conscientes e que por difusão entraram no esquecimento... Vasto fundo submarino onde todas as culturas, todos os estudos, todas as diligências dos espíritos e das vontades, todas as revoltas sociais, todas as lutas empreendidas encontram-se reunidas num recipiente informe... Os elementos passionais da vida dos indivíduos se retiram, extinguiram-se. Subsistem apenas os dados provenientes do mundo exterior, mais ou menos transformados e digeridos. É do mundo externo que é feito esse inconsciente... Nascido da vida social, esse humus pertence à sociedade. A espécie e o indivíduo contam pouco, as únicas referências são as raças e o tempo. Esse enorme trabalho confeccionado na sombra reaparece nos sonhos, nos pensamentos, nas decisões; sobretudo durante os períodos importantes e das reviravoltas sociais, ele é o grande fundo comum, reserva dos povos e dos indivíduos. A revolução e a guerra, como febre, acionam melhor seu movimento... Estando ultrapassada a psicologia individual, recorramos a uma espécie de história natural dos ritmos vulcânicos e dos cursos d'água subterrâneos. Nada há na superfície do globo que não tenha sido subterrâneo (água, terra, fogo). Não há nada na inteligência que não tenha sido digerido e que não tenha circulado nas profundezas.'

(GS V.1, $501[\mathrm{~K} 4,2]$ ) 
Tudo o que foi esquecido, por difusão, tudo o que era consciente e não mais o é, "vasto fundo submarino onde todas as culturas, todos os estudos, todas as diligências dos espíritos e das vontades, todas as revoltas sociais, todas as lutas empreendidas encontram-se reunidas num recipiente informe", sem mais os elementos passionais da vida individual, conformam-se como o inconsciente do esquecimento [inconscient de l'oubli]. Tudo isso reaparece nos sonhos, nos pensamentos, nas decisões etc. O inconscient de l'oubli reaparece como uma "febre", como "pulsão" nas revoluções e guerras, especialmente; como catalizador dos "ritmos vulcânicos e dos cursos d'água subterrâneos" da história, e "nada há na superfície do globo que não tenha sido subterrâneo (água, terra, fogo). Não há nada na inteligência que não tenha sido digerido e que não tenha circulado nas profundezas". Ora, o inconsciente do esquecimento é o passado oprimido da XVII tese sobre o conceito de história (GS I.2, 702-703). A metapsicologia, transposta dos limites individuais até os limites da história e do coletivo (Kleiner 1986, 506, 512), mais uma vez aparece de maneira cifrada, anunciada discretamente por Benjamin. Passado oprimido, passado recalcado; inconsciente do esquecimento, inconsciente cultural.

O inconsciente do esquecimento, mencionado apenas uma vez em toda obra das Passagens, certamente não é um dos conceitos cruciais da obra benjaminiana, mas auxilia na compreensão do fundamento não-intencional que a consciência histórica possui. A memória involuntária individual, cuja forma coletiva é a imagem dialética, constitui o fundamento da consciência histórica ou de se estar em uma história que permite penetrar sua inconsciência, pois "a imagem dialética é definida como a memória involuntária que redime a humanidade" (GS I.1, 1233). Nesse sentido, ao constituir a história de maneira imperceptível, o inconscient de l'oubli apenas é inteligível por meio da memória involuntária, ou seja, das estruturas não-intencionais metapsicológicas da (in)consciência.

O inconscient de l'oublit ${ }^{14}$, destarte, permite o melhor entendimento da articulação, na maior parte das vezes tácita, que Benjamin realiza entre a ideia de inconsciente (freudiana, proustiana, surrealista) e os conceitos de memória involuntária (proustiana), esquecimento, imagem dialética e toda a metapsicologia em geral para fundamentar teoricamente a "consciência histórica" que é também inconsciência. A ideia benjaminiana de inconsciente, seria, portanto, mais abrangente do que a freudiana, ainda que se corresponda com as suas exigências, tal como seu caráter escondido e necessariamente passado.

\footnotetext{
14 Prefere-se o conceito de inconsciente de esquecimento ao de inconsciente coletivo [kollektive Unbewn $\beta t e]$ para efeito argumentativo. Benjamin, no fragmento $[\mathrm{K} 6,1]$, cita uma passagem de Seelenprobleme der Gegenwart (1932), de Carl Gustav Jung, na qual o inconsciente coletivo aparece como manifestação atemporal da história do mundo, em oposição à nossa imagem consciente momentânea. Mas nada indica a sua simpatia pelo conceito especificamente junguiano. A indisposição de Benjamin em relação a Jung torna-se clara, no entanto, não por meio desse fragmento, mas em uma carta enviada à Fritz Lieb, de 09 de julho de 1937, na qual registra a sua vontade de demonstrar a "armadura fascista" por trás da psicologia junguiana. "Eu tinha uma crítica da psicologia junguiana, na qual eu havia prometido mostrar-me a sua armadura fascista. Isso também foi adiado. Passo a trabalhar agora sobre Baudelaire" (GS V.2, 1162). Portanto, apesar da ideia de "inconsciente coletivo" carregar de modo genérico algo análogo ao que Benjamin investiga e propõe, opto por um conceito novo, mobilizado pelo trabalho das passagens de maneira declaradamente articulada com a sua teoria da história.
} 


\section{BREVE Nota ConClusiva SOBRE A FORÇA INCONSCIENTE DO PASSADO}

Reconhecer o papel central do tempo passado para a configuração da experiência humana não se caracteriza necessariamente como um gesto político reacionário ou conservador. Ao contrário, do ponto de vista fenomenológico e sobretudo metafísico, esse reconhecimento da função essencial do fenômeno passado para a devida constituição das experiências individuais e coletivas apenas ressalta de modo ontológico que não há existência ex nibilo ${ }^{15}$ - síntese do antigo princípio lógico que afirma que nada advém do nada. Isto é, apesar da história da ideia de tempo organizar três modalidades temporais essenciais - o passado, o presente e o futuro -, não deve restar dúvidas quanto à característica especial do modus temporal passado como o tempo elementar e questão principal para qualquer exame sobre a temporalidade; pois se tempo é basicamente um dos nomes dados ao fenômeno da transitoriedade dos estados gerais da realidade, quer dizer, o fenômeno da passagem, pode-se afirmar que há tempo ou que o tempo passa somente e na medida que há passado.

Não é um acaso que o derradeiro texto de Benjamin se dedique precisamente à ideia de história e enfatize o tempo passado como fundamento da existência - particularmente na tese II. No texto "Sobre o conceito de história", Benjamin reafirma suas conclusões sobre a metapsicologia da experiência do tempo, e solicita ao pensamento histórico que se volte para o passado em busca dos momentos precisos quando a força existencial - ou messiânica, nas palavras dele - inconsciente do passado reclama sua atualização, isto é, tornar-se ato ou objeto de compreensão e elaboração. Trata-se não de momentos especiais, mas da própria atividade corriqueira da (in)consciência, do pensamento, cujo elemento existencial fundamental é o tempo passado e suas variadas manifestações veladas - escondidas de si mesmo -, as quais nem por isso deixam de exercer sua força sobre a realidade; ao contrário, por se manter esquecida, certa memória renova a cada momento o seu poder inconsciente sobre nós. Para Benjamin, portanto, mais do que expor e explicar a força inconsciente do passado, caberia ao historiador desafiar e questionar os porquês de sua forma, pois somente assim se tornaria realmente possível compreendê-la de um ponto de vista teórico sobre a história.

\section{REFERÊNCIAS}

BENJAMIN, Walter; TIEDEMANN, Rolf; SCHWEPPENHAUSER, Hermann. Gesammelte Schriften. Frankfurt am Main: Suhrkamp, 1991. (GS)

BENJAMIN, Walter; GÖDDE, Christoph; LONITZ, Henri. Gesammelte Briefe. Frankfurt am Main: Suhrkamp, 2000. (GB)

BENJAMIN, Walter. Obras Escolbidas III. Charles Baudelaire um lírico no ange do capitalismo. Trad. José Carlos Martins Barbosa e Hemerson Alves Baptista. São Paulo: Editora Brasiliense, 2004.

BERGSON, Henri. Matière et mémoire: essai sur la relation du corps à l'esprit. Paris: PUF, 1990 [1896].

BRETON, André. Manifestes du Surréalisme. Paris: Folio, 1985.

15 Parafraseio aqui as palavras Michel Maffesoli em entrevista ao professor Rodrigo Coppe, no suplemento Estado da Arte (2020). 
DE CARVALHO, Augusto. O papel da tradição na construção do mundo histórico. Revista Antiteses, v. 12, p. 487-509, 2019a.

DE CARVALHO, Augusto. Sobre o conceito de passado em Walter Benjamin. In: DE CARVALHO, Augusto; BENTIVOGLIO, Julio. (Org.). Walter Benjamin: testemunho e melancolia. Serra: Milfontes, 2019b.

DERRIDA, Jacques. La voix et le phénomène. Introduction au problème du signe dans la phénoménologie de Husserl. Paris : PUF, 1967.

FÈVE, Annaïk. "L'aprés-coup de la mémoire". In: Revue Française de Psychanalyse LXX [3]. Paris : PUF, 2006.

FREUD, Sigmund. Gesammelte Werke. London: Imago, 1941. (GW)

FREUD, Sigmund. Studienausgabe. Frankfurt am Main: S. Fischer Verlag, 1975. (SA)

FÜRNKÄS, Josef. Surrealismus als Erkenntnis: Walter Benjamin - Weimarer Einbahnstraße und Pariser Passagen. Stuttgart: JB Metzler, 1988.

GADAMER, Hans-Georg. Le problème de la conscience historique. Louvain: Publications Universitaires de Louvain, 1963.

GAGNEBIN, Jeanne-Marie. "Entre sonho e vigília: quem sou eu?”. In: PROUST, Marcel. No caminho de Swann - Em busca do tempo perdido. São Paulo: Globo, 2006.

GAGNEBIN, Jeanne Marie. Limiar, aura e rememoração: ensaios sobre Walter Benjamin. São Paulo: Editora 34, 2014.

GAGNEBIN, Jenne-Marie. RESENHA: Nadine Werner. Archäologie des Erinnerns. Sigmund Freud in Walter Benjamins 'Berliner Kindheit'. Revista Limiar 3[6], 2016.

GAY, Peter. Freud. Uma vida para nosso tempo. São Paulo: Cia das Letras, 1988.

KITTSTEINER, Heinz D. Walter Benjamin's Historicism. New German Critique 39 [2], 1986.

KLEINER, Barbara. L'éveil comme catégorie centrale de l'experiénce historique dans le Passagen-Werk de Benjamin. In: WISMANN, Heinz (Dir.). Walter Benjamin et Paris, Colloque international. Paris: Les Éditions du Cerf, 1986.

KLÜNERS, Martin. Geschichtsphilosophie und Psychoanalyse. Göttingen: V\&Runipress, 2013.

LACAN, Jacques. Le Séminaire - livre XI - Les quatre concepts fondamentaux de la psychanalyse. Paris : Seuil, 1973.

LÖWY, Michael; BRANT, W. N. C. Walter Benjamin: aviso de incêndio: uma leitura das teses 'Sobre o conceito de história'. São Paulo: Boitempo, 2005.

MATOS, Olgaria C. F. O iluminismo visionário: Benjamin, leitor de Descartes e Kant. São Paulo: Brasiliense, 1993.

MAFFESOLI, Michel.; COPPE, Rodrigo. O Estado da Arte. O Estado de São Paulo, 7 de julho de 2020. Disponível em: https:/ / estadodaarte.estadao.com.br/entrevistamaffesoli-ea-coppe/

MOSÈS, Stéphane. L'Ange de l'Histoire. Paris: Éditions Gallimard, 2006.

OTTE, Georg. 'Dizem-me que sou louco': as epistemologias poéticas de Baudelaire e Benjamin. Alea [online] 9[2], 2007.

PROUST, Marcel. Du côté de chez Swann. Paris: Éditions Gallimard, 1988.

RANKE, Leopold von. "Historisch-politische Zeitschrift" (band 1). In: Sämmtliche Werke. Leipzig: Verlag von Duncker \& Humblot, 1867.

RAULET, Gérard. Benjamin Historismus-Kritik. In: STEINER, Uwe (Hrg.). Walter Benjamin (1892-1940) zum 100. Geburtstag. Bern; Berlin; Frankfurt a. M.; New York; Paris; Wien: Peter Lang, 1992.

RAULET, Gérard. Chockerlebnis, mémoire involontaire und Allegorie. Zu Benjamins Revision seiner Massenästhetik in 'Über einige Motive bei Baudelaire'. Zeitschrift für Kritische Theorie 2, 1996. 
ROSENZWEIG, Franz. Der Stern der Erlösung. Freiburg im Breisgau: Universitätsbibliothek, 2002.

ROUANET, Sergio Paulo. Édipo e o anjo: itinerários freudianos em Walter Benjamin. Rio de Janeiro: Tempo Brasileiro, 1981.

RÜSEN, Jörn. Teoria da História. Uma teoria da história como ciência. Curitiba: Editora UFPR, 2015.

SARLO, Beatriz. Tempo Passado. Cultura da Memória. Belo Horizonte: Cia das Letras e Editora UFMG, 2007.

SCHLOSSMAN, Beryl. Benjamin's Über Einige Motive bei Baudelaire: The Secret Architecture of Correspondances. MLN (German Issue) 107[3], 1992.

SCHMIDER, Christine; WERNER, Michael. Das Baudelaire-Buch. In: LINDNER, Burkhardt. Benjamin Handbuch: Leben-Werke-Wirkung. Stuttgart; Weimar: J. B. Metzler, 2011.

VETÖ, Miklos. Le passé selon Bergson. Archives de Philosophie 68[1], 2005.

WEIGEL, Sigrid. Body-and Image-Space: Re-reading Walter Benjamin. London and New York: Routledge, 1996.

WENTZER, Thomas. Bewahrung der Geschichte. Die hermeneutische Philosophie Walter Benjamins. Bodenheim: Philo Verlagsgesellschaft, 1998.

WERNER, Nadine. Archäologie des Erinnerns. Sigmund Freud in Walter Benjamins Berliner Kindheit. Göttingen: Wallstein, 2015.

WIEGMANN, Jutta. Psychoanalytische Geschichtstheorie : eine Studie zur Freud-Rezeption Walter Benjamins. Bonn: Bouvier, 1989.

ZAHAVI, Dan. Phenomenology of Consciousness. In: BANKS, William (Ed.). Encyclopedie of Consciousness. Amsterdam; Boston; Heidelberg; London; New York; Oxford; Paris; San Diego; San Francisco; Singapore; Sydney; Tokyo: Elsevier; Academic Press, 2009.

METAPSICOLOGIA SOBRE A FORÇA INCONSCIENTE DO PASSADO ARTIGO SUBMETIDO EM 31/08/2020 • ACEITO EM 05/12/2020

DOI | https://doi.org/10.5216/rth.vi2.65368

REVISTA DE TEORIA DA HISTÓRIA | ISSN 2175-5892

\section{@)}

ESTE E UM ARTIGO DE ACESSO LIVRE DISTRIBUIDO NOS TERMOS DA LICENÇA CREATIVE COMMONS ATTRIBUTION, QUE PERMITE USO IRRESTRITO, DISTRIBUIÇÃO E REPRODUÇÃO EM QUALQUER MEIO, DESDE QUE O TRABALHO ORIGINAL SEJA CITADO DE MODO APROPRIADO 